\title{
Developing an Accessibility Index to Inform Housing First Policy: A Critical Evaluation of Social Services in Edmonton Eden McDonald-Yale and Andree Patenaude
}

\begin{abstract}
Unique among housing initiatives, Housing First operates on the principle that every person has the right to a safe and secure home regardless of housing readiness. The Housing First Support Program, operated by Homeward Trust Edmonton, is currently providing over 2,500 Edmontonians with secure housing and the supports needed in the transition from homelessness into housing. The program is intended to last 12 months, gradually reducing a client's support until they are self-sufficient; however, this may be difficult for some clients, especially if they experience poor accessibility to the services and amenities they require to achieve housing stability. In particular, youth experiencing homelessness require supports that are tailored to their needs and that aid in the transition from adolescence to adulthood. As youth make up 17\% ( $\mathrm{n}=312)$ of Housing First clients, it is imperative that the services, centres, and supports necessary to breaking the cycle of homelessness are accessible to them at this critical stage in development. With this project, we mapped the locations of current Housing First clients aged 12-24 in relation to the services and amenities they may require to achieve housing stability. After identifying these services and amenities, we used a gravity model to create an Accessibility Index. This Accessibility Index highlights the service accessibility of current Housing First clients, and can be used in the future to identify areas of need and opportunities for increasing accessibility.
\end{abstract}

\section{INTRODUCTION}

This project arose out of concern around the issue of homelessness in Edmonton. As of 2014, the most recent point-in-time homeless count for which full results are available, there were 2307 homeless Edmontonians (Homeward Trust Edmonton, 2014). We partnered with Homeward Trust Edmonton, a local non-profit which strives to address homelessness in our city. Homeward Trust Edmonton has been coordinating the Housing First program in Edmonton since 2005. Housing First, as a principle and a program, operates on the premise that housing stability is required before people who are homeless or at-risk of homelessness can address the personal and structural issues which exacerbate the cycle of homelessness. These issues such as mental health concerns, addictions, or finding employment, require coordinated support from community organizations and multiple levels of government. Our project aims to determine whether these services are accessible to Housing First clients. This research focuses on youth aged 12-24 in the Housing First program. Youth have different service needs from adults in the process of achieving housing stability (Karabanow \& Naylor, 2013). Primarily, youth are experiencing social and developmental transitions unique to their age group. They are not only dealing with the transition from homelessness into a housed lifestyle, but also experiencing important transitions in their social roles and expectations.

This project aims to assess relative accessibility of services essential to escaping the cycle of poverty and to ultimately achieve housing stability. We use the term housing stability as defined by Sylvestre and colleagues (2009): "the ongoing ability of individuals to access, over the course of their lives, housing that promotes their optimal health and quality of life" (p. 200). We selected three key elements from the End Poverty Edmonton Strategy and the Plan for Ending Homelessness Alberta which help to break the cycle of poverty and homelessness as well as to 
achieve housing stability: 1) reduce barriers to getting information and accessing City programs and services; 2) help people navigate systems in order to access resources and opportunities; and 3) improve timely access to health services and addictions supports (End Poverty Edmonton, 2015; Government of Alberta, 2008). Based on these elements as well as a review of the literature on youth homelessness, we identified the services, supports, and amenities necessary for Housing First clients aged 12-24 to seek information, access healthy opportunities and build supportive relationships.

\section{LITERATURE REVIEW}

There is a lack of research on the issue of homelessness as it relates to government policy as well as literature which is comparative or interdisciplinary in nature (Collins, 2010). Much of the research and reports on homelessness in Canada are completed by not-for-profits and other social agencies. For example, Edmonton's biennial homeless count is organized by Homeward Trust Edmonton. As a result, this literature review relies heavily on grey literature. In addition to the sparse academic research, the definitions of homelessness are varying and incomplete (Chamberlain \& MacKenzie, 1992). Without a nuanced understanding of who the population is, it is impossible to develop methods to effectively amend the situation. While the most obvious inclusion is people who lack shelter and either sleep outdoors or depend on emergency shelters, if only this most visible population is included, researchers neglect the experiences of people elsewhere on the spectrum homelessness (Collins, 2010). Chamberlain and Mackenzie (1992) classify homelessness into three types: primary (people without shelter), secondary (individuals using emergency or short-term accommodations such as staying with family or friends), and tertiary (those living in boarding rooms that lack private amenities or are without security in tenancy). Those experiencing tertiary homelessness are often hidden from homeless counts and other research due to their low visibility on the streets (Collins, 2010). The Canadian Observatory on Homelessness (2012) breaks this definition even further to include a fourth degree of homelessness: those at risk of homelessness. Nonetheless, despite the varying definitions of homelessness used across many jurisdictions, past efforts have largely focused on providing emergency relief rather than working to prevent homelessness or to transition out of homelessness (Minnery \& Greenhalgh, 2007).

The Housing First model works to go beyond emergency relief, by providing homeless individuals with supportive housing immediately upon entering the program (Gaetz, Gulliver, \& Richter, 2014; Government of Canada, 2014). The program's harm reduction strategy does not require individuals to secure employment or participate in treatment for substance use before acquiring housing. Furthermore, because the Housing First intervention strategy uses a personcentred approach, Housing First clients are given a choice in their housing options and emphasis is placed on scattered-site housing in order to encourage social integration and minimize stigma. This further increases the demand for improved accessibility to the services and supports necessary to breaking the cycle of homelessness.

In general, literature on the topic of ending homelessness tends to overlook the factors that may cause people to become homeless, which are unique to each individual. The causes of homelessness can be categorized into structural factors, systems failures, and individual circumstances (The Homeless Hub, 2016). Structural factors are the economic and societal issues that affect individuals' opportunities and social environments, such as inadequate income, 
discrimination, or the lack of affordable housing available. Systems failures occur when networks of care and support fail, resulting in vulnerable people becoming homeless. Individual and relational factors are the personal circumstances of a homeless person, such as traumatic events, physical health problems and disabilities, family violence, or mental health problems (of the individual or family members). For example, many homeless youth have experienced trauma, come from abusive homes, or identify as lesbian, gay, bisexual, or transgender (Edidin, Ganim, Hunter, \& Karnik, 2012). Most often, different factors combine and interact with each other to make an individual homeless.

A structural factor evident in Canada's homelessness dilemma is the lack of affordable housing available. Homelessness emerged as a crisis in Canada after the federal government placed a moratorium on the development of affordable housing in 1993 (Laird, 2007). While the supply of affordable housing remained constant, rental rates increased, resulting in a rapidly worsening homelessness crisis further exacerbated by low vacancy rates and private sector efforts to maximize profits. Since these cuts to housing supports and related social services, the main response to the crisis has been to heavily rely on the provision of emergency services. This shortterm remedy has proved to be more expensive than previous efforts to curb homelessness, as Gaetz (2007) outlines in his report on the cost of homelessness. He argues that in comparison to maintaining the status quo, providing long-term shelter and necessary supports is a more costeffective system of rapidly rehousing individuals and working to prevent individuals from falling into the cycle of homelessness. The latter point is critical to any efforts to end homelessness; if governments do not actively enact preventative measures, individuals will continue to suffer from housing instability and the issue of homelessness will continue to worsen (Apicello, 2010).

Given the ambiguity surrounding the term housing stability, Sylvestre and colleagues worked to provide a nuanced understanding of what it means (Sylvestre, Ollenberg, \& Trainor, 2009). In this report, we define housing stability as going beyond solely maintaining stable housing to include access to opportunities for wellbeing (such as health professionals and recreation centres) and information (such as schools, libraries and drop-in centres). Housing stability is especially imperative for youth, who are learning to live independently after homelessness as well as transitioning to adulthood (Gaetz, 2014). Thus, increasing youths' access to the services which promote housing stability is important because youth are experiencing major changes both developmentally and in their social roles. Homelessness is more than an event for most street youth; rather, it is a process that leads to social exclusion. This exclusion results in vulnerability both socially and economically (Winland, 2013). This challenging experience, therefore, requires a comprehensive approach that moves past the traditional service model of emergency response to focus on stable housing, income, education and training, life skills, wellness, and other additional supports such mental health services (Gaetz, 2014).

This comprehensive model is referred to as a "system of care" approach and involves an adaptive and interactive network which aims to provide access to necessary services and supports across various jurisdictions (Hodges, Ferreira, Israel, \& Mazza, 2006). This type of approach also necessitates the integration of services and providers, as the problems most homeless and at-risk youth face are more complex than can be adequately managed by one agency alone (Kelly \& Caputo, 2007). Furthermore, these problems often reflect broader social concerns and are not limited to individual behaviour. For example, many homeless gay, lesbian, and transgender youth 
were abused or forced to leave home as a result of their sexuality (Kidd \& Shahar, 2008). Almost universally, homeless youth have experienced traumatic events or suffered from abuse (Klodawsky, Aubry, \& Farrell, 2006).

\section{METHODOLOGY}

\section{Data}

Homeward Trust Edmonton provided data regarding the age and location of Housing First clients within Edmonton as of December 2015, with a total of 2528 records. 425 were deleted due to insufficient information. After geocoding the records, we calculated kernel density through ArcGIS to create heat maps comparing the spatial trends of both adult $(n=1223)$ and youth $(n=312)$ clients (see Appendix A). We classified youth as those between the ages of 12 to 24 while adults were identified as age 25 and older.

We found the locations of health services, mental health services, educational facilities, youth services, social services, parks, city-owned recreation centres, and public libraries from Edmonton's Open Data Catalogue. We used the tabulate intersection function on ArcGIS to determine the postal code for each event. To find where grocery stores and food banks were located, we used Google Maps to find the postal code and geocoded these entries as well. Only supermarket chains were included.

Our analyses were completed at the FSA-level to protect the identities and information of Housing First clients. FSAs (Forward Sortation Areas) are geographical areas in Canada designated by the first three digits of a postal code. There are thirty-eight FSAs within the City of Edmonton. To calculate relative accessibility, we used a gravity model from Bhat and colleagues' work on urban accessibility indices (2002). We determined the number of events per FSA and entered the information into the model using the following formula:

$$
A_{i}=\ln \left[\frac{i}{J} \sum_{j} \frac{O_{j}}{d_{J}^{\alpha}}\right]
$$

Where $A_{i}$ is relative accessibility, $O_{j}$ is the number of events in each FSA, $d_{j}$ is the shortest street network distance between FSAs, and $\propto$ varies depending on the nature of the trip: 2.0347 (work), 2.5 (shopping), or 3.0751 (recreation).

\section{Limitations}

There are several limitations to our analysis:

1. Grocery stores and food banks were located using Google Maps as the zoning shapefile found on Edmonton's Open Data Catalogue is unable to completely or accurately report existing services and amenities.

2. We measured accessibility in terms of distance. Measures of cost or travel time would increase the accuracy and complexity of this analysis.

3. The Housing First client data is only a snapshot of December 2015 and thus cannot reflect changes in housing over time. Tracking the location of clients over several years would allow for a more thorough understanding of trends in accessibility needs as well as possible opportunity areas. 
4. Due to limited data, we cannot discern youth living independently from those who are with guardians.

\section{RESULTS \& DISCUSSION}

We found that the areas with the highest accessibility to services and amenities tend to be in the core, with few exceptions. Adult clients are also concentrated in the downtown core, meaning that many have reasonable spatial accessibility to the supports necessary to achieving housing stability; however, areas with the highest density of youth are on the peripheries to the northeast and southeast. These areas often have the worst accessibility. Figures 1 and 2 below show a comparison between the locations of adult and youth clients in relation to their relative geographic accessibility to employment and youth centre services. A separate suite of services was used for each age group as the literature indicates that homeless and at-risk youth require different services than adults. This pattern can be seen in almost every comparison: mental health services, grocery stores and food banks, recreation centres, and public libraries. The accessibility maps for all of these amenities are attached in Appendix B.

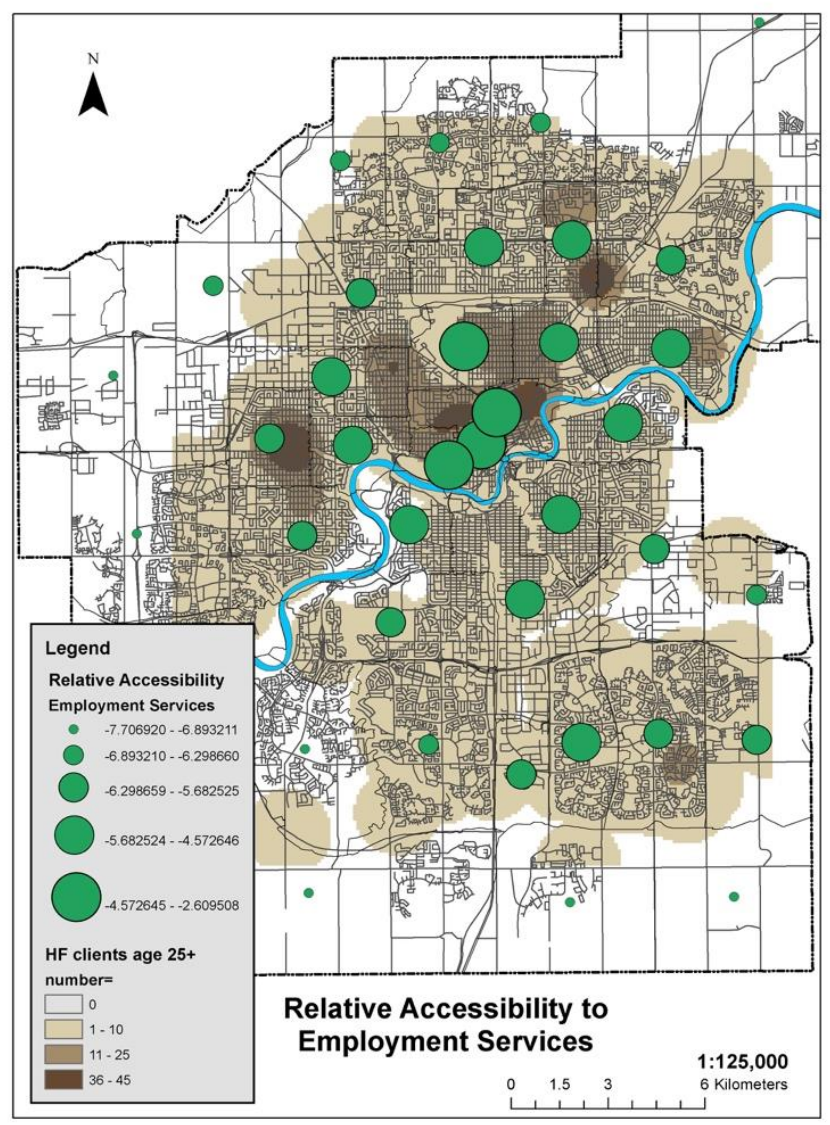

Figure 1: Adult client density in relation to relative accessibility of employment services. Areas with the best accessibility are in the downtown core, where the highest density of clients are also located. 


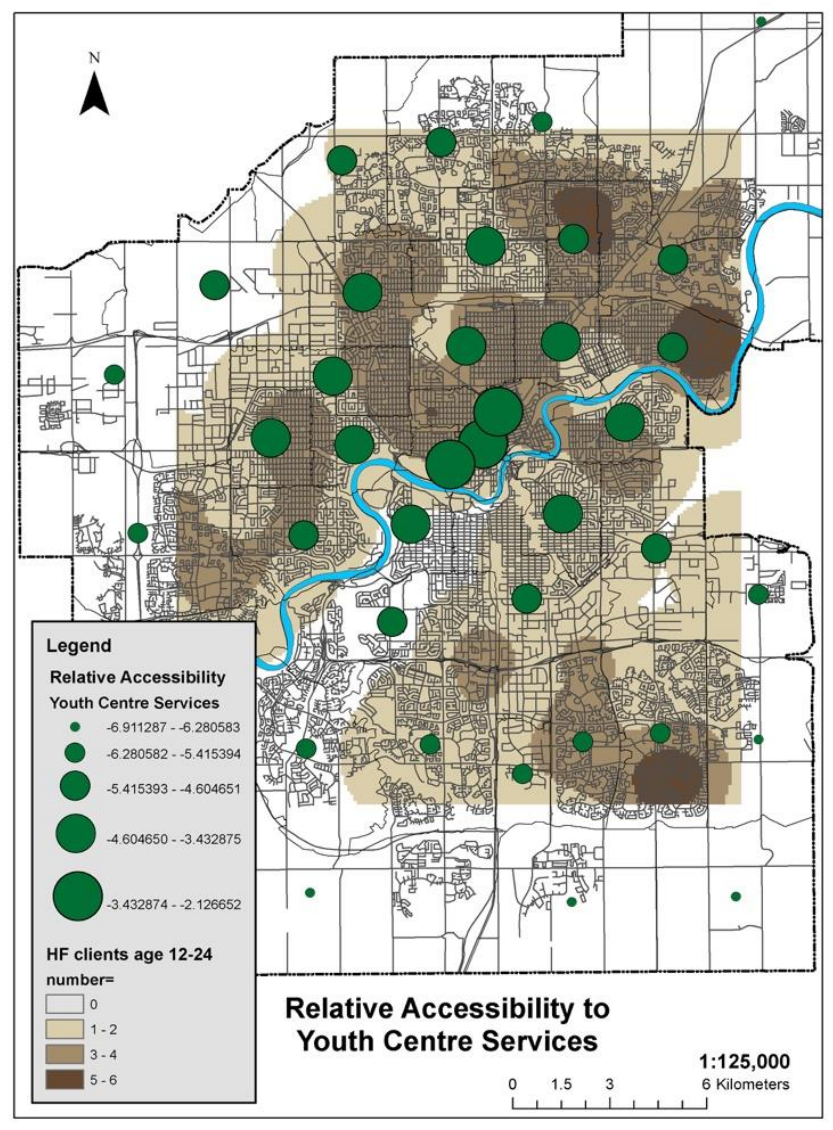

Figure 2: Youth client density in relation to relative accessibility of youth centre services. Areas with the best accessibility are again in the downtown core, but the highest densities of youth clients are found on the periphery.

Of particular interest is the Mill Woods area, located to the southeast with high youth client density and the farthest away from the areas of highest accessibility. This could be a good example of an opportunity area for new social services to be established, and particularly those for homeless and at-risk youth, as there is a high density of youth but they experience low accessibility to most services and amenities. A long-term approach would be to develop new services; however, our analyses are not in depth or conclusive enough to recommend this approach, nor can we confirm that this client density is continually an overall trend. Similarly, as Housing First clients choose their housing location, we cannot advocate for encouraging clients to simply move closer to necessary supports. Thus, we turn to the integrated management approach to improve client accessibility to services at their existing locations.

Two programs which might be integrated to increase accessibility to services would be the Leisure Access Pass and the ETS low income bus pass. These programs are already offered to lowincome Edmontonians. While people may or may not be aware of these opportunities, the application process for these programs includes some understanding of government documents and requires paperwork including tax documents. As Housing First clients are initially homeless, the majority of clients are assumed to have low incomes. Therefore, it might be meaningful to 
remove some of the barriers to accessing these programs by ensuring that all Housing first clients receive the Leisure Access Pass and the ETS low income bus pass without applying for the passes and filing additional paperwork. By removing barriers through the integrated management of these programs, the cost and time required to access services can be reduced. Therefore, it may be possible to increase accessibility without decreasing the distance between clients and services. Ideally, integrated management would save client time and money, as well as remove the stress of having to complete additional paperwork and retell their story. The intention behind integrating the management of these programs is to apply the City of Edmonton priorities listed in the introduction of this paper: 1) reduce barriers to getting information and accessing City programs and services; 2) help people navigate systems in order to access resources and opportunities; and 3) improve timely access to health services and addictions supports.

The effectiveness of the integrated management of Housing First and existing city programs such as those mentioned above could be an area for further research. Although our project focused on the concept of accessibility to youth Housing First clients, there are other groups for which we could analyse accessibility to services. Canada's colonial past is essential to discussions about homelessness (Gaetz, Gulliver, \& Richter, 2014). First Nations, Métis, and Inuit people are overrepresented in homeless counts in almost every Canadian community, and make up 47\% of Edmonton's homeless population as of 2014 (Laird 2007; Gaetz, Gulliver, \& Richter, 2014; Homeward Trust Edmonton, 2014). Further research into the supports necessary for indigenous people to maintain housing stability is needed, and may be a potential application for this research and resulting accessibility index. We could also use this process to understand more about other age groups such as seniors or families and their accessibility to services. Lastly, our research does not conclusively identify areas of opportunity, although the neighbourhoods identified might be in need of more social services. An analysis of the opportunities and constraints, as well as the costs and benefits of such a development would more accurately identify opportunity areas for new social service development.

\section{CONCLUSION}

Our research has shown that based on distance, youth Housing First clients have lower relative accessibility to social services and amenities than their adult counterparts. This finding suggests that accessibility could be improved if other factors such as cost and trip time are reduced through integrated management. The literature identifies homelessness and specifically youth homelessness in Canada to be an area of interest and concern on both individual and structural levels. This project is a contribution to discerning how the recently rehoused homeless population in Edmonton is distributed and how we can better leverage existing city programs and services to meet the needs of at-risk populations. Integrated management can reduce the barriers to accessing various programs offered by the City of Edmonton, greatly improving accessibility to necessary services and supports without necessarily decreasing the distance between clients and services.

\section{ACKNOWLEDGEMENTS}

We would like to acknowledge the continued support and advice of Dr. Manish Shirgaokar throughout the project. We are also thankful to Homeward Trust Edmonton and Edmonton's Open Data Catalogue for providing the data. 


\section{REFERENCES}

Apicello, Jocelyn. "A paradigm shift in housing and homeless services: applying the population and high-risk framework to preventing homelessness." Open Health Services and Policy Journal 3 (2010): 41-52.

Bhat, C., Handy, S., Kockelman, K., Mahmassani, H., Gopal, A., Srour, I., \& Weston, L. (2002). Development of an Urban Accessibility Index: Formulations, Aggregation, and Application. Austin, Texas: The University of Texas. Retrieved from https://www.utexas.edu/research/ctr/pdf reports/4938 4.pdf

Canadian Observatory on Homelessness. (2012). Canadian definition of homelessness. Homeless Hub. Retrieved from http://homelesshub.ca/sites/default/files/COHhomelessdefinition.pdf

Causes of Homelessness. (2016). The Homeless Hub. Retrieved 7 April 2016, from http://homelesshub.ca/abouthomelessness/homelessness-101/causes-homelessness

Chamberlain, C., \& MacKenzie, D. (1992). Understanding contemporary homelessness: Issues of definition and meaning. Australian Journal of Social Issues, 27, 274-297.

Collins, D. (2010). Homelessness in Canada and New Zealand: A Comparative Perspective on Numbers and Policy Responses. Urban Geography, 31(7), 932-952. http://dx.doi.org/10.2747/0272-3638.31.7.932

Edidin, J. P., Ganim, Z., Hunter, S. J., \& Karnik, N. S. (2012). The mental and physical health of homeless youth: a literature review. Child Psychiatry \& Human Development, 43(3), 354-375.

End Poverty Edmonton. (2015). End Poverty in a Generation: A Strategy. Edmonton. Retrieved from http://www.edmonton.ca/city government/documents/PDF/EndPovertyInAGeneration_Strategy.pdf

Gaetz, S. (2012). The Real Cost of Homelessness: Can we save money by doing the right thing? Toronto: Canadian Homelessness Research Network Press.

Gaetz, S. (2014). Coming of age: Reimagining the response to youth homelessness in Canada. Canadian Homelessness Research Network.

Gaetz, S., Gulliver, T., \& Richter, T. (2014). The state of homelessness in Canada 2014. Toronto: The Homeless Hub Press. Retrieved from http://homelesshub.ca/sites/default/files/SOHC2014.pdf

Government of Alberta. (2008). Supporting healthy and successful transitions to adulthood: A plan to prevent and reduce youth homelessness. Retrieved from http://www.humanservices.alberta.ca/documents/plan-to-preventand-reduce-youth-homelessness.pdf

Government of Canada. (2014). Housing First Approach. Employment and Social Development Canada. Retrieved from http://www.esdc.gc.ca/eng/communities/homelessness/housing first/approach/index.shtml

Hodges, S., Ferreira, K., Israel, N., \& Mazza, J. (2006). Strategies for system of care development: Making change in complex systems. Tampa, FL: Department of Child and Family Studies, Louis de la Parte Florida Mental Health Institute, The Research and Training Center for Children's Mental Health, University of South Florida.

Homeward Trust Edmonton. (2014). 2014 Edmonton Point-in-Time Homeless Count. Edmonton: Homeward Trust Edmonton.

Karabanow, J., \& Naylor, T. (2013). Pathways Towards Stability: Young People's Transitions. In S. Gaetz, B. O'Grady, K. Buccieri, J. Karabanow \& A. Marsolais, Youth Homelessness in Canada: Implications for Policy and Practice (pp. 39-52). Toronto: Canadian Homelessness Research Network Press.

Kelly, K., \& Caputo, T. (2007). Health and Street/ Homeless Youth. Journal of Health Psychology, 12(5), 726-736. http://dx.doi.org/10.1177/1359105307080594

Kidd, S., \& Shahar, G. (2008). Resilience in homeless youth: The key role of self-esteem. American Journal of Orthopsychiatry, 78(2), 163-172.

Klodawsky, F., Aubry, T., \& Farrell, S. (2006). Care and the Lives of Homeless Youth in Neoliberal Times in Canada. Gender, Place \& Culture, 13(4), 419-436. http://dx.doi.org/10.1080/09663690600808577

Laird, G. (2007). Homelessness in a growth economy: Canada's 21st century paradox. Calgary, Alberta: Sheldon Chumir Foundation for Ethics in Leadership.

Minnery, J., \& Greenhalgh, E. (2007). Approaches to homelessness policy in Europe, the United States, and Australia. Journal of Social Issues, 63(3), 641-655.

Sylvestre, J., Ollenberg, M., \& Trainor, J. (2009). A model of housing stability for people with serious mental illness. Canadian Journal of Community Mental Health, 28(1), 195-207.

Winland, D. (2013). Reconnecting with Family and Community: Pathways Out of Youth Homelessness. In S. Gaetz, B. O'Grady, K. Buccieri, J. Karabanow \& A. Marsolais, Youth Homelessness in Canada: Implications for Policy and Practice (1st ed., pp. 15-38). Toronto: Canadian Homelessness Research Network Press. 


\section{APPENDIX A}
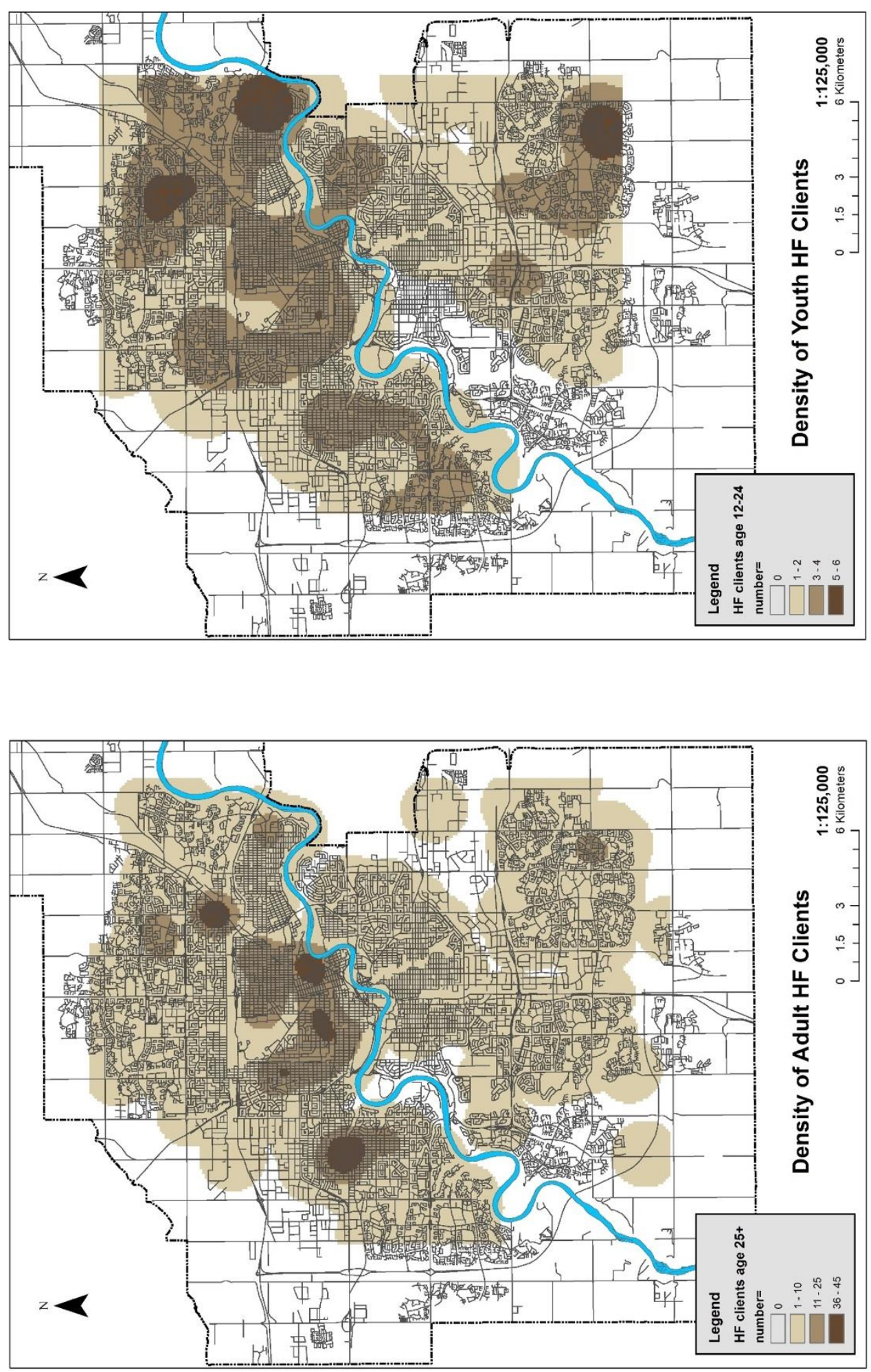


\section{APPENDIX B}
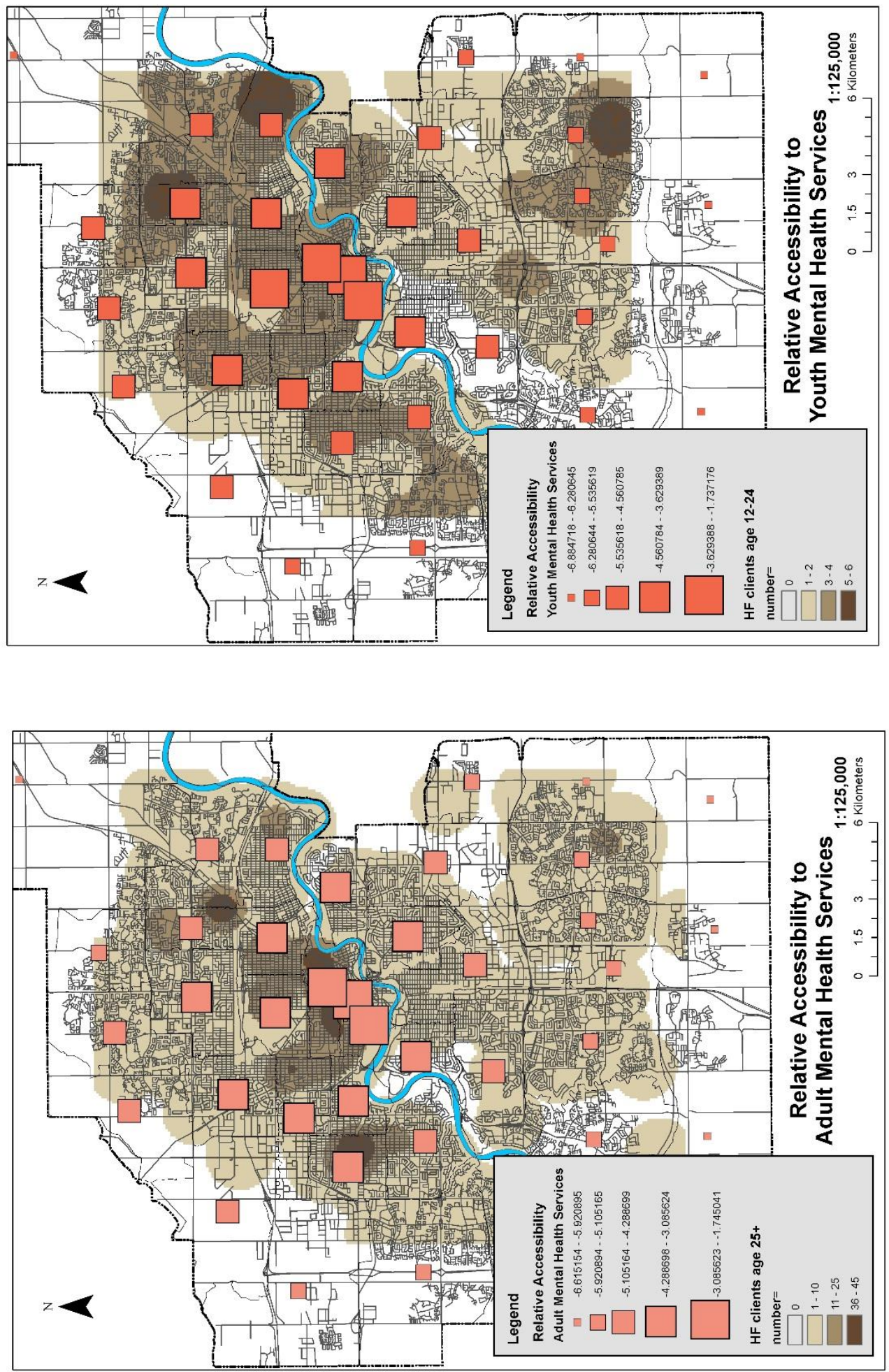

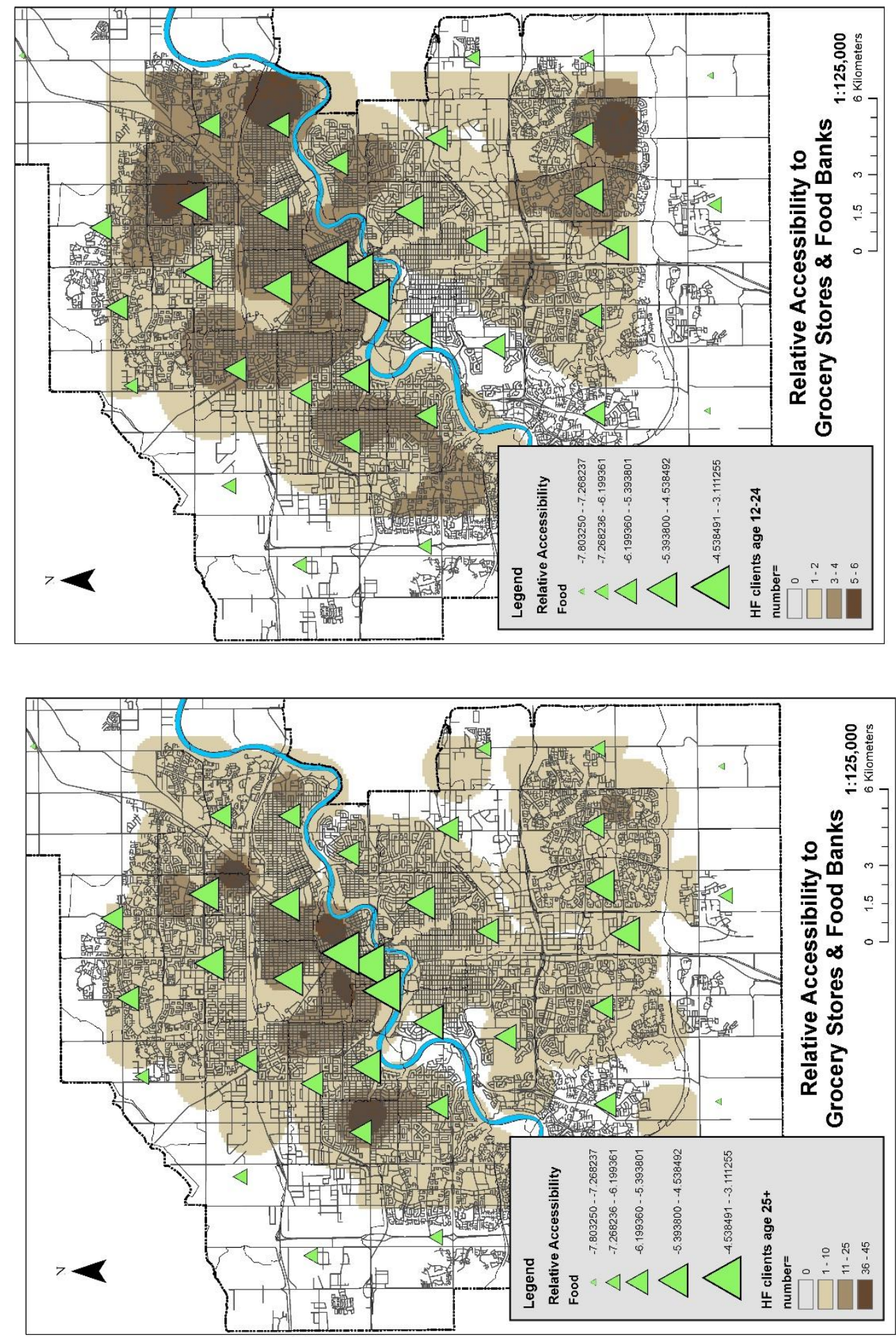

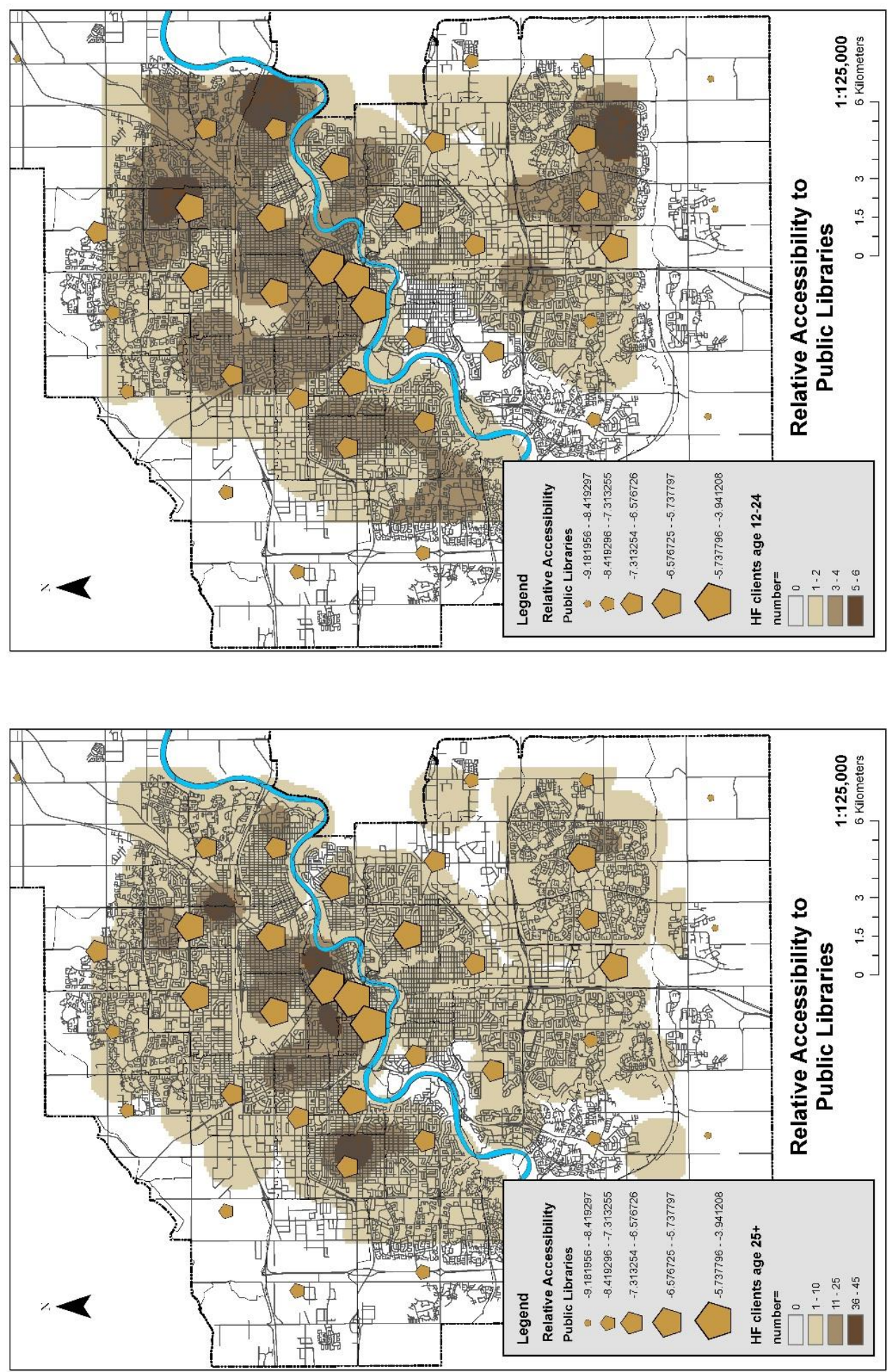

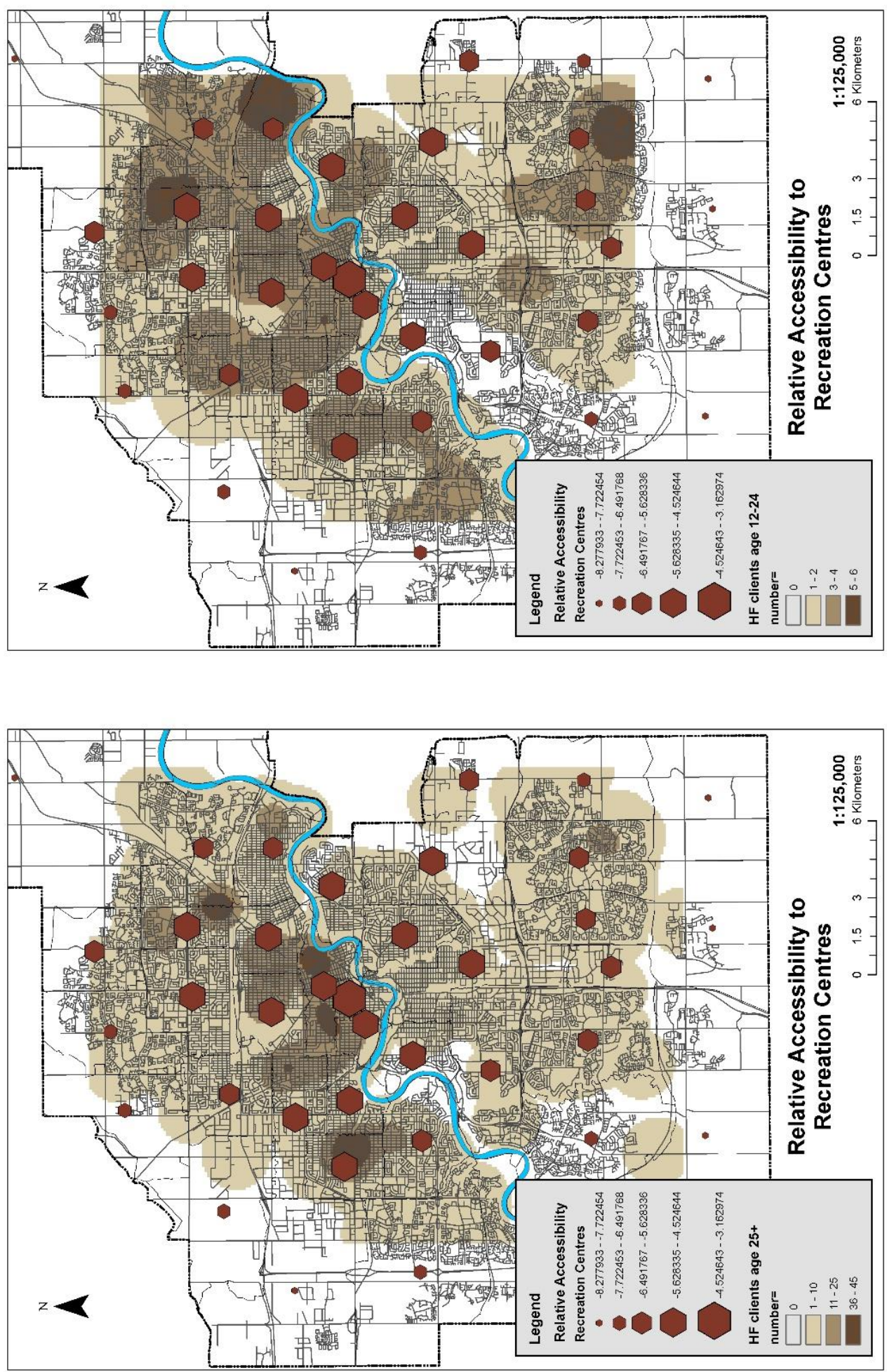